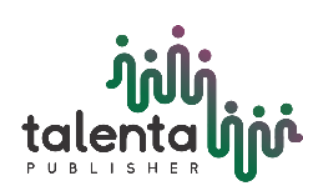

Jurnal Teknik Kimia USU

Vol. 09, No. 2, September $2020 \mid 51-56$

ISSN : 2337-4888

Homepage: https://talenta.usu.ac.id/jtk

\title{
Produksi Biodiesel tanpa Gliserol dari Minyak Kelapa Sawit dengan Variasi Massa Co-solvent dan Waktu Reaksi
}

\author{
Biodiesel Production without Glycerol from Palm Oil with \\ Variations in Co-solvent Mass and Reaction Time
}

\author{
Elvianto Dwi Daryono*, Angga Puji Prasetyo, Syaiful Bahri, Eliya Maya Sista \\ Jurusan Teknik Kimia, Fakultas Teknologi Industri, Institut Teknologi Nasional Malang \\ Jalan Bendungan Sigura-gura No. 2, Malang, 65145, Indonesia \\ *Email: elviantodaryono@lecturer.itn.ac.id
}

\begin{abstract}
Abstrak
Bahan bakar dari minyak bumi semakin berkurang persediannya seiring dengan bertambahnya industri dan jumlah penduduk. Sumber energi alternatif terbarukan yang potensial untuk menggantikan BBM adalah biodiesel. Proses pembuatan biodiesel yang umum dilakukan adalah proses transesterifikasi dengan produk sampingnya gliserol yang proses pemisahannya sulit. Metode yang digunakan dalam penelitian ini adalah metode interesterifikasi, yaitu dengan mengganti gugus metil alkohol dengan gugus metil dari metil asetat dengan produk samping triasetin. Kondisi operasi proses adalah massa minyak kelapa sawit 250 gram, massa katalis $\mathrm{KOH} 1 \%$ wt. minyak, suhu reaksi $60{ }^{\circ} \mathrm{C}$, kecepatan pengadukan $800 \mathrm{rpm}$, massa co-solvent metil ester $(0,5,10,15,20 \%$ wt. minyak) dan waktu reaksi (30 menit, 60 menit, 90 menit). Hasil dari penelitian yang telah dilakukan didapat yield tertinggi dengan penambahan co-solvent metil ester sebanyak $20 \%$ berat minyak pada waktu reaksi 30 menit yaitu sebesar 92,43\%. Produk biodiesel yang dihasilkan memenuhi SNI 7182:2015 yaitu nilai angka asam < $0,5 \mathrm{mg}-\mathrm{KOH} / \mathrm{g}$.
\end{abstract}

Kata kunci: biodiesel, interesterifikasi, co-solvent

\begin{abstract}
Petroleum fuels are increasingly reduced in line with the increasing industry and population. A potential alternative renewable energy source to replace fuel is biodiesel. The process of making biodiesel that is commonly done is the process of transesterification with glycerol byproducts which is difficult to separate. The method used in this study is the method of interesterification, namely by replacing the methyl alcohol group with a methyl group from methyl acetate with triacetin byproducts. The operating conditions of the process are 250 grams of palm oil mass, $1 \% \mathrm{wt} \mathrm{KOH}$ catalyst mass. oil, reaction temperature $60{ }^{\circ} \mathrm{C}$, stirring speed $800 \mathrm{rpm}$, mass of co-solvent methyl ester $(0,5,10,15,20 \%$ wt. oil) and reaction time (30 minutes, 60 minutes, 90 minutes). The results of the research have been obtained the highest yield with the addition of co-solvent methyl ester of $20 \%$ by weight of oil in the reaction time of 30 minutes is $92.43 \%$.The biodiesel product produced meets SNI 7182:2015 which is an acidic value $<0.5 \mathrm{mg}-\mathrm{KOH} / \mathrm{g}$.
\end{abstract}

Keywords: biodiesel, interesterification, co-solvent

\section{Pendahuluan}

Kebutuhan metil ester semakin meningkat tiap tahun karena merupakan raw material yang penting bagi industri kimia. Metil ester saat ini telah digunakan untuk membuat minyak diesel sebagai bahan bakar alternatif. Metil ester termasuk bahan oleokimia dasar, turunan dari trigliserida (minyak atau lemak) yang dapat dihasilkan melalui proses esterifikasi, transesterifikasi, dan interesterifikasi. Bahan baku pembuatan metil ester antara lain minyak kelapa sawit, minyak kelapa, minyak jarak, minyak kedelai, minyak biji pepaya dan lainnya.
Biodiesel adalah bahan bakar mesin diesel yang terbuat dari bahan-bahan renewable dengan komposisi senyawa alkil ester. Kelebihan biodiesel antara lain yaitu tidak menimbulkan polusi, dan dapat digunakan tanpa modifikasi mesin diesel. Biodiesel dapat diperoleh dari minyak tumbuhan yang berasal dari sumber daya alam yang dapat diperbaharui seperti minyak nabati, lemak binatang, dan minyak goreng bekas/jelantah, melalui esterifikasi dan atau transesterifikasi [1].

Persediaan kelapa sawit sebagai bahan utama pembuatan biodiesel sangat berpotensi dari tahun ketahun, mengingat jumlah yang melimpah. Menurut 
data dari Direktorat Jenderal Perkebunan produksi minyak sawit pada tahun 2016 sebesar 33.500.691 ton dan luas area perkebunan sebesar 11.672.861 hektar. Produksi dan luas area perkebunan setiap tahun mengalami peningkatan, sehingga Indonesia berpotensi dapat meningkatkan jumlah produksi biofuel khususnya biodiesel [2].

Proses umum yang dilakukan untuk pembuatan biodiesel adalah transesterifikasi, dimana dihasilkan produk samping gliserol yang proses pemisahannya relatif sulit. Standar biodiesel Indonesia mensyaratkan kandungan gliserol bebas pada biodiesel maksimal 0,02\% massa [3]. Dalam industri biodiesel, langkah pemisahan bisa dikurangi dengan menghasilkan biodiesel melalui proses tanpa pembentukan gliserol atau produk samping air. Salah satu pilihan menarik adalah mensintesis biodiesel melalui reaksi interesterifikasi minyak nabati dengan menggunakan metil atau etil asetat sebagai reaktan dan bukan alkohol berantai pendek. Interesterifikasi kimiawi minyak dengan metil/etil asetat akan menghasilkan metil ester (biodiesel) dan triasetin, sedangkan gliserol tidak akan diproduksi dalam reaksi ini. Kandungan $10 \%$ triasetin pada biodiesel masih menghasilkan biodiesel yang memenuhi kualitas [4]. Triasetin dikenal sebagai bahan bakar bio-aditif yang dapat meningkatkan kualitas bahan bakar dalam hal viskositas, stabilitas oksidasi, dan arus awan serta memiliki fungsi sebagai agen anti-knocking untuk bahan bakar diesel [5]. By product proses interesterifikasi yaitu triasetin, harga jualnya lebih tinggi dibandingkan gliserol [6].

Permasalahan utama dalam reaksi interesterifikasi adalah kelarutan trigliserida dan metil asetat yang terbatas. Reaksi satu fase dapat dibentuk dengan menambahkan pelarut yang dapat meningkatkan kelarutan minyak, pelarut tersebut disebut sebagai co-solvent [7]. Penelitian yang telah dilakukan selama ini menggunakan co-solvent dengan harga yang relatif mahal dan perlu proses separasi pada akhir reaksi dengan pemanasan. Hal ini tentunya akan menambah biaya produksi biodiesel itu sendiri. Maka untuk mengatasi hal tersebut adalah dengan menggunakan metil ester sebagai co-solvent, yang akan menghemat biaya produksi karena tidak perlu proses pemisahan co-solvent di akhir reaksi [8].

Penelitian sebelumnya pernah dilakukan dengan proses yang sama tetapi tidak menggunakan cosolvent, dengan kondisi optimum pada penelitian tersebut diperoleh pada konsentrasi katalis $\mathrm{KOH} 1 \%$, rasio mol metil asetat-minyak jarak 6:1, suhu reaksi pada $60^{\circ} \mathrm{C}$ dan waktu reaksi selama 1 jam, dengan yield biodiesel sebesar 87,63\% [1]. Pada penelitian interesterifikasi trigliserida, mendapatkan yield metil oleat $83 \%$ pada suhu reaksi $120^{\circ} \mathrm{C}$, rasio mol metil asetat:minyak $=20: 1$, katalis feri sulfat $7,5 \%$, waktu reaksi 12 jam dengan menggunakan co-solvent metil miristat 7,7 g/L [9].

Tujuan penelitian adalah untuk mengetahui massa co-solvent metil ester yang optimal dalam proses pembuatan biodiesel menggunakan metode interesterifikasi serta mengetahui waktu reaksi yang dibutuhkan untuk mencapai hasil yang optimal.

\section{Teori}

\section{Metil Ester (Biodiesel)}

Metil ester adalah senyawa ester yang terbentuk dari asam lemak yang berasal dari tumbuhan maupun hewan yang bereaksi dengan alkohol. Proses konvensional yang banyak dilakukan untuk pembuatan metil ester adalah proses transesterifikasi, karena bisa menghasilkan yield yang relatif tinggi dalam waktu yang singkat. Tetapi kelemahannya adalah dengan adanya produk samping gliserol. Metode tanpa produk samping gliserol untuk menghasilkan biodiesel adalah interesterifikasi, yaitu mereaksikan minyak/lemak dengan alkil asetat dengan produk samping triasetin [10]. Metil ester umumnya diproduksi dari refined vegetable oil (minyak murni) melalui proses transesterifikasi dan interesterifikasi. Proses tersebut untuk mengubah trigliserida dari minyak/lemak menjadi alkil ester asam lemak.

Biodiesel merupakan bahan bakar minyak yang dapat diperbaharui. Bahan bakar minyak ini berasal dari bahan baku yang dapat diperbaharui seperti tumbuhan dan hewan [11]. Biodiesel mempunyai sifat fisik yang menyerupai solar sehingga bisa langsung digunakan dalam segala perbandingan.

\section{Minyak Kelapa Sawit (CPO (Crude Palm Oil))}

Produksi minyak kelapa sawit di Indonesia meningkat dari tahun ke tahun, dan Indonesia merupakan penghasil minyak kelapa sawit terbesar di dunia. Minyak kelapa sawit diekspor dalam bentuk CPO. Kandungan utama dalam minyak kelapa sawit adalah trigliserida sekitar 93\%. Kandungan gliserida lainnya adalah digliserida $4,5 \%$ dan monogliserida $0,9 \%$. Minyak kelapa sawit juga mengandung impurities lain yaitu FFA dan gum. Minyak kelapa sawit kemasan mempunyai kadar FFA $0,124 \%$ dan kadar air 0,0496\% [12]. Kandungan dan komposisi asam lemak penyusun minyak kelapa sawit ditunjukkan pada Tabel 1 .

Tabel 1. Kandungan asam lemak dalam CPO [13]

\begin{tabular}{|l|l|}
\hline \multicolumn{1}{|c|}{ Jenis asam lemak } & Komposisi (\%) \\
\hline Asam Laurat (C12:0) & $>0,5$ \\
\hline Asam Miristat (C14:0) & $0,5-2,0$ \\
\hline Asam Palmitat (C16:0) & $39,3-47,5$ \\
\hline Asam Palmitoleat (C16:1) & $>0,6$ \\
\hline Asam Stearat (C18:0) & $3,5-6,0$ \\
\hline Asam Oleat (C18:1) & $36,0-44,0$ \\
\hline Asam Linoleat (C18:2) & $9,0-12,0$ \\
\hline Asam Linolenat (C18:3) & $>0,5$ \\
\hline Asam Arakidat (C20:0) & $>0,1$ \\
\hline Asam Gadoleinat (C20:1) & $>0,4$ \\
\hline
\end{tabular}




\section{Interesterifikasi}

Interesterifikasi minyak dan lemak dengan metil/etil asetat sangat menarik karena bisa bersamaan mensintesis biodiesel dan bahan bakar bio-aditif. Reaksi interesterifikasi seperti ditunjukkan pada Gambar 1. adalah reaksi yang bersifat reversibel dengan tiga tahapan reaksi [5]. Pada reaksi interesterifikasi terjadi pertukaran gugus antara dua senyawa ester dengan bantuan katalis. Katalis yang digunakan bisa bersifat homogen $(\mathrm{NaOH}, \mathrm{KOH})$, biokatalis, katalis heterogen dan tanpa katalis. Reaksi biodiesel ini dilakukan menggunakan substrat yang berasal dari minyak nabati sebagai sumber trigliserida dan dilakukan melalui rute non-alkohol yaitu menggunakan metil asetat.

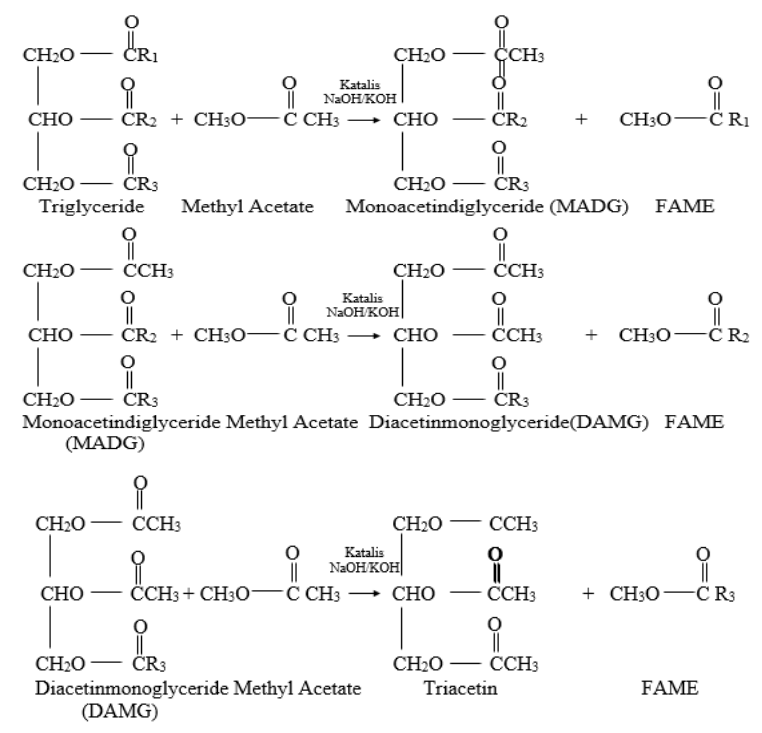

Gambar 1. Reaksi Interesterifikasi

Faktor-faktor yang mempengaruhi pembuatan biodiesel dengan metode interesterifikasi adalah: 1. Suhu

Pada umumnya reaksi dapat dijalankan pada suhu mendekati titik didih metil asetat $\left(50-60^{\circ} \mathrm{C}\right)$ pada tekanan atmosfer. Laju reaksi akan naik bersamaan dengan dengan kenaikan suhu reaksi. Jika suhu semakin tinggi, maka akan semakin banyak energi yang dapat digunakan oleh reaktan untuk mencapai energi aktivasi. Hal ini menyebabkan fraksi tumbukan antar molekul reaktan semakin besar untuk kemudian melakukan reaksi, sehingga laju reaksi meningkat. Penggunaan temperatur reaksi $60^{\circ} \mathrm{C}$ pada reaksi interesterifikasi untuk menghindari menguapnya semua metil asetat yang bertitik didih $57^{\circ} \mathrm{C}$ [1].

2. Waktu reaksi

Waktu reaksi berbanding lurus dengan jumlah produk yang dihasilkan. Jika reaksi telah mencapai kesetimbangan, penambahan waktu reaksi tidak akan berpengaruh tetapi malah justru menurunkan jumlah produk yang dihasilkan khusunya pada reaksi reversibel. Pada interesterifikasi minyak jarak pagar dengan etil asetat mendapatkan yield $14 \%$ pada waktu reaksi 6 jam [5].

\section{Katalis}

Fungsi katalis adalah mempercepat reaksi dengan menurunkan energi aktivasi tanpa menggeser letak kesetimbangan reaksi. Tanpa katalis, reaksi Interesterifikasi baru dapat berjalan pada suhu sekitar $250^{\circ} \mathrm{C}$. Katalis selain untuk mempercepat reaksi juga untuk menurunkan kondisi operasi. Dengan katalis basa reaksi dapat berjalan pada suhu kamar, sedangkan katalis asam pada umumnya memerlukan suhu reaksi diatas $100^{\circ} \mathrm{C}$. Katalis asam cair yang biasa digunakan, misalnya asam sulfat, asam klorida, dan asam sulfonat. Pada interesterifikasi minyak jelantah, mendapatkan yield kasar 87,63\% dengan menggunakan katalis $\mathrm{KOH} 1 \%$ dan waktu reaksi 60 menit [1].

4. Pengadukan

Pengadukan bertujuan untuk mendapatkan campuran reaksi yang homogen. Dengan pengadukan akan mempercepat laju perpindahan massa. Pada interesterifikasi minyak bunga matahari mendapatkan fraksi massa FAME 5\% pada suhu reaksi $50^{\circ} \mathrm{C}$ dan kecepatan pengaduk $600 \mathrm{rpm}$ [10].

5. Perbandingan reaktan

Stoikiometri reaksi interesterifikasi memerlukan 3 mol metil asetat untuk setiap mol trigliserida untuk menghasilkan 3 mol ester asam dan 1 mol triasetin. Supaya reaksi interesterifikasi bergeser ke arah produk maka digunakan excess metil asetat atau dengan segera memisahkan salah satu produk hasil reaksi. Lebih banyak metil asetat yang digunakan, maka semakin memungkinkan reaktan untuk bereaksi lebih cepat. Pada interesterifikasi minyak kelapa sawit dengan bio-katalis, mendapatkan konversi $82 \%$ dengan rasio mol TG:metil asetat $=1: 12$ dan waktu reaksi 50 jam [6].

\section{Metodologi Penelitian Bahan}

Bahan yang digunakan yaitu minyak kelapa sawit (Sunco), metil asetat (p.a), methanol (p.a), natrium hidroksida $(\mathrm{NaOH})$, kalium hidroksida $(\mathrm{KOH})$, aquadest, indikator $\mathrm{PP}, \mathrm{HCl} 1 \mathrm{~N}$ dan asam fosfat.

\section{Prosedur Penelitian \\ Penentuan Kadar Air}

Menimbang minyak sebanyak 10 gram, dan memasukkan ke dalam oven pada suhu $105^{\circ} \mathrm{C}$ selama 30 menit. Mendinginkan pada desikator hingga mencapai suhu kamar dan menghitung kadar air minyak kelapa sawit dengan persamaan (1).

Kadar air $=\frac{\text { massa awal }- \text { massa akhir }}{\text { massa } \text { awal }} \times 100 \%$

Uji FFA [13]

Menimbang 20 gram minyak dalam erlenmeyer. Memanaskan minyak sampai suhu $65^{\circ} \mathrm{C}$, Memasukkan etanol $96 \%$ sebanyak $50 \mathrm{~mL}$ dan 3 tetes indikator PP ke dalam erlenmeyer. Mendinginkan larutan pada suhu kamar dan menitrasi larutan dengan larutan $\mathrm{KOH} 0,1 \mathrm{~N}$ sampai terjadi perubahan warna 
menjadi pink. Mencatat volume titrasi yang dibutuhkan dan menyatakan asam lemak bebas sebagai \% FFA. Perhitungan \% FFA menggunakan persamaan (2) yaitu:

$\%$ FFA $=\frac{\text { mlКонхNКон } х \text { ВM asam lemak }}{\text { massa sampel } 1000} \times 100 \%$

Jika hasil FFA > $2 \%$ maka dilakukan proses esterifikasi sampai bahan baku mempunyai FFA < $2 \%$. Jika FFA $<2 \%$ maka dapat melakukan proses transesterifikasi dan interesterifikasi.

Tahap Pembuatan Co-solvent [14]

Reaksi transesterifikasi dilakukan dengan menimbang minyak 250 gram, katalis $\mathrm{NaOH} 1 \%$ berat minyak, kecepatan pengadukan $100 \mathrm{rpm}$, waktu reaksi 1 jam, suhu reaksi $60^{\circ} \mathrm{C}$, dan rasio molar minyak:metanol = 1:6. Menambahkan $\mathrm{HCl} 1 \mathrm{~N}$ pada hasil reaksi untuk menetralisasi katalis dan memasukkan ke dalam corong pemisah selama \pm 12 jam supaya terpisah menjadi 2 lapisan. Lapisan atas adalah metil ester yang akan digunakan sebagai cosolvent.

\section{Tahap Interesterifikasi}

Menyiapkan minyak kelapa sawit sebanyak 250 $\mathrm{g}$, kemudian mencampurkan minyak kelapa sawit dan co-solvent dan dipanaskan sampai suhu $60^{\circ} \mathrm{C}$. Mencampurkan $\mathrm{KOH} 1 \%$ dan metil asetat kedalam labu leher tiga dan dipanaskan sampai suhu $60^{\circ} \mathrm{C}$. Memasukkan campuran minyak dan co-solvent ke dalam labu leher tiga saat suhu telah tercapai. Memanaskan dan mengaduk campuran tersebut pada temperatur $60^{\circ} \mathrm{C}$ dengan waktu 30,60, dan 90 menit dengan kecepatan pengadukan $800 \mathrm{rpm}$ serta massa co-solvent $0,5,10,15,20 \%$ dari berat minyak. Hasil reaksi kemudian ditambahkan asam pospat untuk menetralisasi katalis dan dimasukkan ke alat centrifuge untuk pemisahan.

\section{Tahap pemurnian}

Menyiapkan dan memasukkan biodiesel yang sudah terbentuk ke dalam tabung centrifuge. Mengatur kecepatan putaran alat centrifuge dengan kecepatan 1500 rpm dan lama waktu 1 menit. Setelah 1 menit akan terbentuk 2 lapisan yaitu lapisan atas adalah metil ester, minyak sisa reaksi, metil asetat sisa reaksi dan sedikit air serta lapisan bawah yaitu triasetin, garam kalium fosfat hasil reaksi netralisasi $\mathrm{KOH}$ dan air. Lapisan atas kemudian dilakukan destilasi pada suhu $110^{\circ} \mathrm{C}$ untuk menghilangkan metil asetat sisa reaksi dan air yang terikut. Langkah terakhir adalah menyaring produk metil ester yang masih kelihatan keruh dengan kertas saring sehingga didapatkan metil ester yang jernih.

\section{Tahap analisa}

Produk biodiesel yang didapatkan dilakukan analisa densitas, angka asam dan komposisi metil ester dengan menggunakan GC.

Menentukan Yield Kasar

Perhitungan yield kasar dihitung dengan persamaan (3).

Yield $(\%)=\frac{\text { Massa hasil reaksi }}{\text { Massa minyak awal }} \times 100 \%$

\section{Hasil dan Pembahasan}

Dari hasil analisa awal didapatkan konsentrasi FFA minyak awal adalah $0,1569 \%$, kadar air minyak awal 0,015\% dan densitas minyak awal 0,91 g/ml.

Tabel 2. Data densitas dan angka asam metil ester

\begin{tabular}{|c|c|c|c|}
\hline $\begin{array}{c}\text { Massa Co- } \\
\text { Solvent } \\
(\%)\end{array}$ & $\begin{array}{l}\text { Waktu } \\
\text { Reaksi } \\
\text { (menit) }\end{array}$ & $\begin{array}{c}\text { Densitas } \\
\left(\mathrm{g} / \mathrm{cm}^{3}\right)\end{array}$ & $\begin{array}{l}\text { Angka Asam } \\
\text { (mg-KOH/g) }\end{array}$ \\
\hline \multirow{3}{*}{0} & 30 & 0,9 & 0,29 \\
\hline & 60 & 0,9 & 0,28 \\
\hline & 90 & 0,9 & 0,29 \\
\hline \multirow{3}{*}{5} & 30 & 0,9 & 0,30 \\
\hline & 60 & 0,9 & 0,28 \\
\hline & 90 & 0,9 & 0,28 \\
\hline \multirow{3}{*}{10} & 30 & 0,9 & 0,29 \\
\hline & 60 & 0,9 & 0,29 \\
\hline & 90 & 0,9 & 0,28 \\
\hline \multirow{3}{*}{15} & 30 & 0,9 & 0,29 \\
\hline & 60 & 0,9 & 0,30 \\
\hline & 90 & 0,9 & 0,29 \\
\hline \multirow{3}{*}{20} & 30 & 0,9 & 0,28 \\
\hline & 60 & 0,9 & 0,30 \\
\hline & 90 & 0,9 & 0,29 \\
\hline
\end{tabular}

Pada Tabel 2 didapatkan nilai densitas yang tidak sesuai dengan standar SNI $\left(0,85-0,89 \mathrm{~g} / \mathrm{cm}^{3}\right)$ [3] pada semua variasi waktu reaksi dan penambahan cosolvent. Hal ini dikarenakan terdapatnya kandungan minyak yang belum bereaksi sehingga densitas metil ester masih mendekati densitas minyak awal yaitu $0,91 \mathrm{~g} / \mathrm{ml}$. Untuk nilai angka semua memenuhi SNI yaitu maks. 0,5 mg-KOH/g [3].

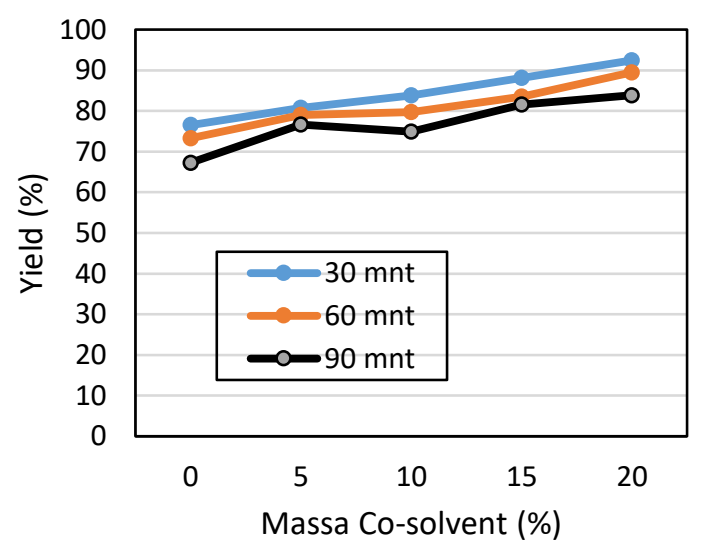

Gambar 2. Hubungan antara yield (\%) dan massa cosolvent $(\%)$ terhadap waktu reaksi (menit) 
Pada Gambar 2. terlihat bahwa yield tertinggi didapat pada penambahan co-solvent $20 \%$ massa minyak dengan waktu reaksi 30 menit yaitu sebesar $92,43 \%$. Ini sesuai dengan dengan teori bahwa terjadi peningkatan yield seiring dengan penambahan cosolvent. Ini dikarenakan sifat co-solvent yang mampu meningkatkan kelarutan reaktan sehingga membentuk satu fase. Dengan terbentuknya satu fase maka reaksi akan cepat berjalan dan produk metil ester akan cepat terbentuk. Penelitian sebelumnya mendapatkan yield kasar 87,63\% dengan waktu reaksi 60 menit [1]. Gambar 3. Menunjukkan kromatogram metil ester pada kondisi optimum yaitu dengan penambahan $\mathrm{co}$ solvent metil ester $20 \%$ pada waktu reaksi 30 menit.

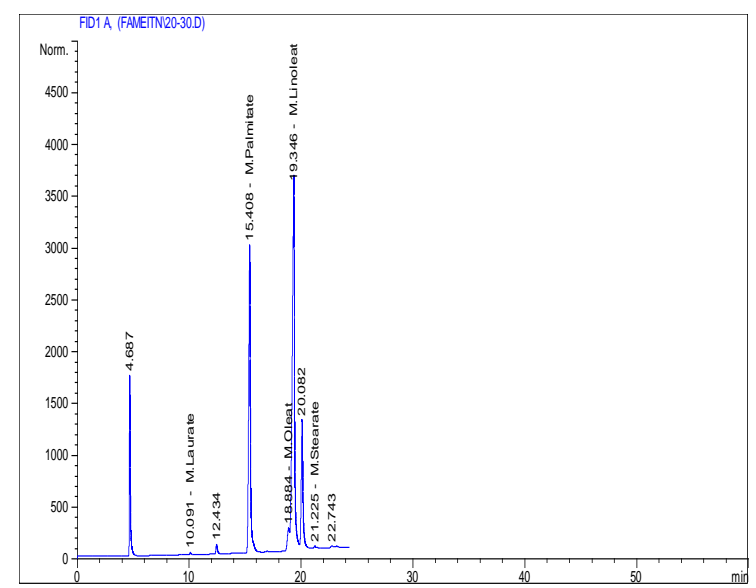

Gambar 3. Kromatogram metil ester pada waktu reaksi 30 menit dengan penambahan co-solvent $20 \%$

Tabel 3. Hasil analisa GC komposisi metil ester pada waktu reaksi 30 menit dengan penambahan co-solvent $20 \%$

\begin{tabular}{|l|l|}
\hline \multicolumn{1}{|c|}{ Metil Ester } & Komposisi (\%) \\
\hline Metil laurat & 0,67 \\
\hline Metil palmitat & 66,67 \\
\hline Metil oleat & 6,08 \\
\hline Metil linoleat & 26,32 \\
\hline Metil stearat & 0,17 \\
\hline
\end{tabular}

Tabel 3 menunjukkan komposisi metil ester pada kondisi optimum proses interesterifikasi yaitu dengan penambahan co-solvent metil ester $20 \%$ pada waktu reaksi 30 menit. Komposisi metil ester terbesar yang didapat adalah metil palmitat $66,67 \%$ dan ini sesuai dengan komposisi asam lemak minyak kelapa sawit terbesar yaitu asam palmitat.

\section{Kesimpulan}

Berdasarkan penelitian pembuatan biodiesel menggunakan metode interesterifikasi dengan variasi massa co-solvent dan waktu reaksi, didapatkan kesimpulan bahwa co-solvent dapat mempengaruhi pembentukan metil ester. Yield tertinggi didapat pada penambahan co-solvent metil ester $20 \%$ berat minyak dengan waktu reaksi 30 menit yaitu sebesar 92,43\%. Produk biodiesel memenuhi SNI untuk angka asam yaitu $<0,5 \mathrm{mg}-\mathrm{KOH} / \mathrm{g}$.

\section{Ucapan Terima Kasih}

Ucapan terima kasih ditujukan kepada Jurusan Teknik Kimia dan juga staf laboratorium Bioenergi Institut Teknologi Nasional Malang yang telah mendukung dan memberikan fasilitas penelitian.

\section{Daftar Pustaka}

[1] I. . Hartono, R., Listiadi, A.P., Bayupramana, "Intensifikasi Biodiesel dari Minyak Jelantah dengan Metode Interesterifikasi dan Pemurnian Dry Washing," J. Teknol. Pengelolaan Limbah, vol. 16, no. 3, pp. 49-56, 2013, [Online]. Available:

http://jurnal.batan.go.id/index.php/jtpl/article/vi ew/1235.

[2] Directorate General of Plantation, "Statistik Perkebunan Indonesia 2014-2016: Kelapa sawit,' Tree Crop Estate Stat. Indones., no. December 2015, p. 79, 2015, [Online]. Available: http://ditjenbun.pertanian.go.id/tinymcpuk/gam bar/file/statistik/2016/SAWIT 2014-2016.pdf.

[3] SNI 7182:2015, "Standar Nasional Indonesia 7182:2015," Standar Nas. Indones. 71822015, no. 1, pp. 1-88, 2015.

[4] A. Casas, J. R. Ruiz, M. J. Ramos, and Á. Pérez, "Effects of triacetin on biodiesel quality," Energy and Fuels, vol. 24, no. 8, pp. 4481-4489, 2010, doi: 10.1021/ef100406b.

[5] R. D. Kusumaningtyas, R. Pristiyani, and H. Dewajani, "A new route of biodiesel production through chemical interesterification of jatropha oil using ethyl acetate," Int. J. ChemTech Res., vol. 9, no. 6, pp. 627-634, 2016.

[6] H. Hermansyah, S. Marno, R. Arbianti, T. S. Utami, and A. Wijanarko, "Interesterifikasi Minyak Kelapa Sawit Dengan Terimobilisasi," J. Tek. Kim. Indones., vol. 8, no. 1, pp. 24-32, 2009.

[7] Muyassaroh, E. D. Daryono and M. I. Hudha, "Biodiesel dari Minyak Jarak Pagar dengan Variasi Penambahan Co-Solvent Dan Waktu Reaksi," Tek. Kim., vol. 7, no. 1, pp. 8-11, 2012.

[8] E. D. Daryono and E. J. Sinaga, "Transesterifikasi palm oil dengan variasi massa co-solvent dan waktu reaksi," Pros. Sentia, vol. 8, no. 2, pp. 13-16, 2016, [Online]. Available: http://sentia.polinema.ac.id/index.php/SENTIA 2016/article/view/126.

[9] Y. Tian, J. Xiang, C. C. Verni, and L. Soh, "Fatty acid methyl ester production via ferric sulfate catalyzed interesterification," Biomass and Bioenergy, vol. 115, no. November 2017, pp. 82-87, 2018, doi: 10.1016/j.biombioe. 2018.04.013.

[10] A. Casas, M. J. Ramos, and Á. Pérez, "New 
trends in biodiesel production: Chemical interesterification of sunflower oil with methyl acetate," Biomass and Bioenergy, vol. 35, no. 5, pp. 1702-1709, 2011, doi: 10.1016/j.biombioe. 2011.01.003.

[11] S. P. Kuncahyo, A. Zuhdi, "Analisa Prediksi Bahan Baku Biodiesel sebagai Suplemen Bahan Bakar Motor Diesel di Indonesia," J. Tek. POMITS, vol. 2, no. 1, p. B-62-B-66, 2013, doi: 10.11113/jt.v56.60.

[12] E. J. Daryono, E.D. Sinaga, "Transesterification of Palm Oil with $\mathrm{NaOH}$ Catalyst Using Cosolvent Methyl Ester," Int. J. ChemTech Res., vol. 9, no. 12, pp. 570-575, 2016.

[13] H. A. Hasibuan, "The Study of Quality and Characteristic on Indonesian Palm Oil and Its Fractionation Products," J. Stand., vol. 14, no. 1, pp. 13-21, 2012, doi: 10.31153/js.v14i1.51.

[14] P. Chitra, P. Venkatachalam, and A. Sampathrajan, "Optimisation of experimental conditions for biodiesel production from alkalicatalysed transesterification of Jatropha curcus oil," Energy Sustain. Dev., vol. 9, no. 3, pp. 1318, 2005, doi: 10.1016/S0973-0826(08)60518-9. 